\title{
Case Report: Multiple hemorrhagic metastases to the brain from primary lung choriocarcinoma [version 1; peer review: 2
}

\section{approved]}

\author{
Sunil Munakomi \\ Department of Neurosurgery, Nobel Teaching Hospital, Biratnagar, Nepal
}

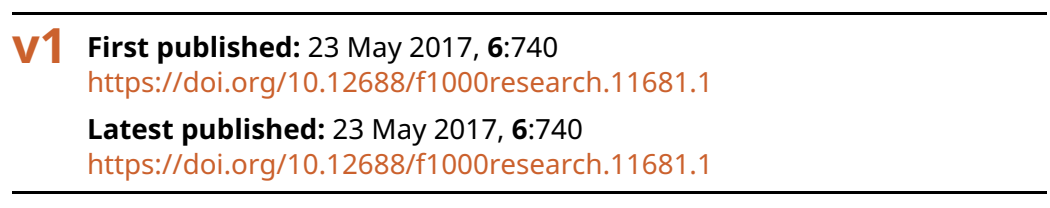

\section{Abstract}

Herein we report a very rare entity of multiple hemorrhagic metastases to the brain from a primary lung choriocarcinoma in a young woman. The patient presented with recent onset of progressive headache, decreased level of consciousness and multiple episodes of vomiting. CT of the head revealed multiple hemorrhagic lesions within the brain. The patient's serum B-human chorionic gonadotrophin was increased. A chest X-ray revealed a right lung mass. The patient urgently underwent operative excision of the lesion in the posterior fossa, so as to prevent impending tonsillar herniation. The histology from the lesion provided the diagnosis of choriocarcinoma. After surgery, ultrasonography of the abdomen and pelvis was normal, and a chest $\mathrm{CT}$ revealed an enhanced and highly vascular right apical lung lesion, suggestive of lung primary choriocarcinoma, with regard to the clinical background. The patient was then started on chemotherapy, following which her serum B-HCG level decreased rapidly. This case highlights the importance of keeping this entity in the differential diagnosis of hemorrhagic lesions in any patients of a child bearing age. Early diagnosis and rapid initiation of multimodal therapy is prudent for ensuring a good outcome from an otherwise rapidly metastasizing and highly vascular lesion.

\section{Keywords}

primary, lung, choriocarcinoma, brain, metastasis

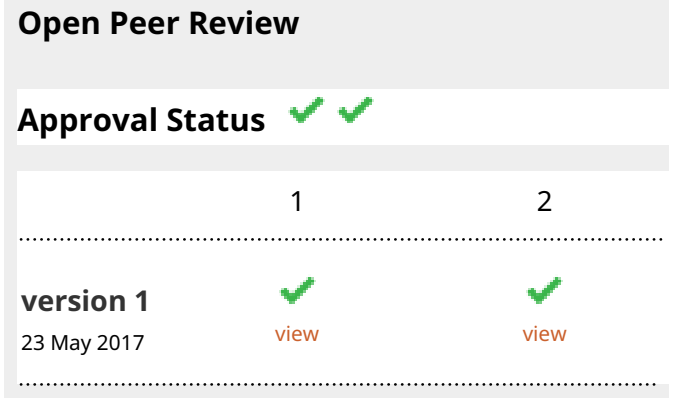

1. Ping Wang, Tianjin Medical University Cancer Institute and Hospital, Tianjin, China

2. Lekhjung Thapa (iD), Neuro and Allied Clinic, Bhairahawa, Nepal

Any reports and responses or comments on the article can be found at the end of the article. 
Corresponding author: Sunil Munakomi (sunilmunakomi@gmail.com)

Competing interests: No competing interests were disclosed.

Grant information: The author(s) declared that no grants were involved in supporting this work.

Copyright: $\odot 2017$ Munakomi S. This is an open access article distributed under the terms of the Creative Commons Attribution License, which permits unrestricted use, distribution, and reproduction in any medium, provided the original work is properly cited.

How to cite this article: Munakomi S. Case Report: Multiple hemorrhagic metastases to the brain from primary lung choriocarcinoma [version 1; peer review: 2 approved] F1000Research 2017, 6:740 https://doi.org/10.12688/f1000research.11681.1

First published: 23 May 2017, 6:740 https://doi.org/10.12688/f1000research.11681.1 


\section{Introduction}

Primary lung choriocarcinoma is an extremely rare entity ${ }^{1}$. Choriocarcinoma is the malignant proliferation of the syncytial cells of trophoblastic origin following gestational events, such as a term pregnancy, molar pregnancy or an abortion. We herein report one such rare case of multiple hemorrhagic metastases to the brain from primary lung choriocarcinoma in a 22 year old young woman. We also review the literature regarding primary lung choriocarcinoma and discuss recent advancements in the management of this disease.

\section{Case report}

A 22 year old woman presented to our emergency department with a history of a recent onset progressive headache for 15 days, followed by decreased level of consciousness and multiple episodes of vomiting for the last 5 days. The patient had a history of normal vaginal delivery one month past. The patient had no history of fever, chills or any rigor associated with these symptoms, and there was no history of abnormal discharge or bleeding from the vagina. There was no other significant past medical and surgical illnesses or any relevant family history. On presentation, the patient was slightly drowsy with a Glasgow Coma Scale of E4V1M3, with bilateral pupils equal and reacting. She had bilateral sixth nerve palsies (left $>>$ right; Figure 1). Neck rigidity was absent. There was no pallor or any lymphadenopathy. Remaining systemic examination was normal. Pelvic and genital examination from a gynecologist did not reveal any abnormal findings.

CT and MRI images of the head revealed multiple hemorrhagic lesions both in the supra and the infra-tentorial compartment with evidence of effacement of the forth ventricle and evolving hydrocephalus (Figure 2 and Figure 3). There was no vascular blush seen within the brain in the MR angiography (Figure 4). Routine chest X-ray revealed the presence of a right lung mass (Figure 5). Urine for pregnancy test was also positive. However, an ultrasound of the abdomen and pelvis was normal. Therefore, choriocarcinoma was suspected and serum B-human chorionic gonadotropin (HCG) levels were assessed, $>2,20,000 \mathrm{mIU} / \mathrm{ml}$ (normal range: $<1 \mathrm{mIU} / \mathrm{ml}$ ). The patient's hemoglobin was $14.5 \mathrm{gm} \%$ (normal range: $12.1-15.1 \mathrm{gm} \%$ ) and a platelet count of 2,15,000 (normal range: $1,50,000-4,00,000)$. Peripheral smear for cytology was normal. Her immune status was normal.

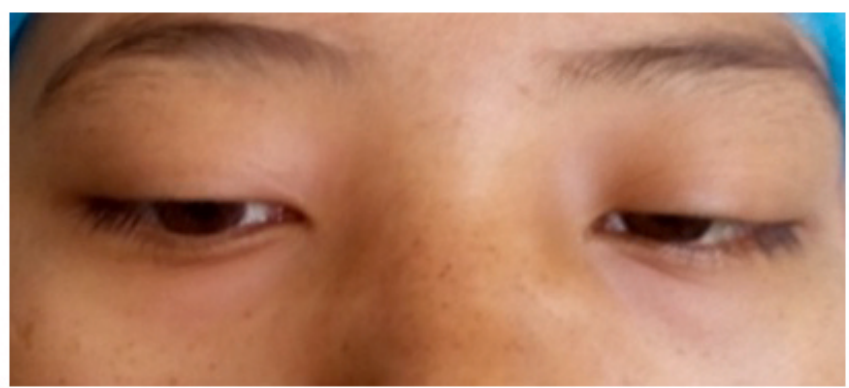

Figure 1. Clinical image showing bilateral sixth nerve palsy in the patient.

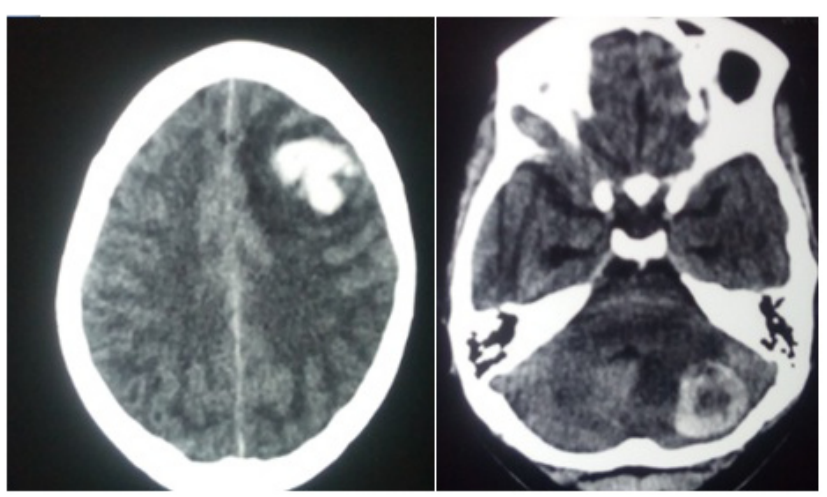

Figure 2. CT head images showing multiple hemorrhagic lesions within the brain.

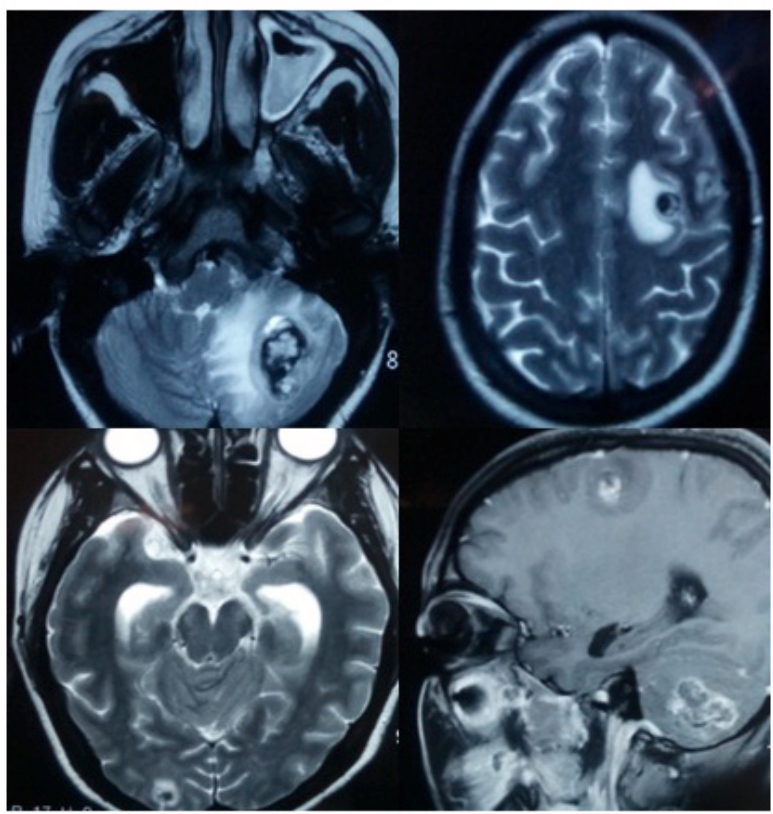

Figure 3. MRI images showing multiple lesions within the brain at different phase of resolution.

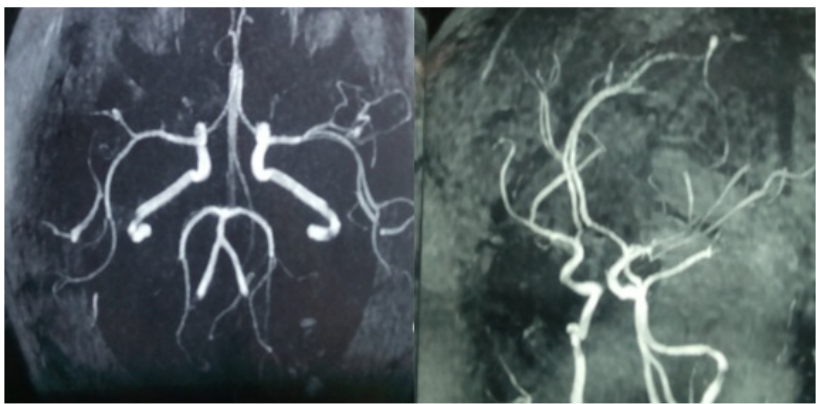

Figure 4. MRI angiography showing absence of any vascular blush or major arterial feeder to the lesions. 


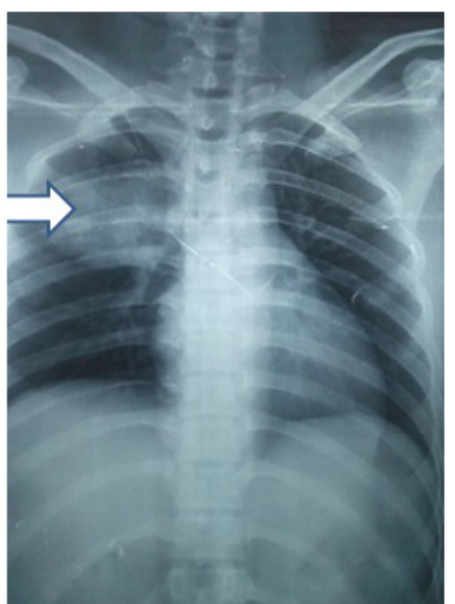

Figure 5. Chest X-ray revealing right sided apical lung lesion.

Consequently, a differential diagnosis of multiple hemorrhagic metastases to the brain from the primary lung choriocarcinoma was made. The patient's husband was informed about the disease condition and the immediate need for the removal of the posterior fossa lesion in order to prevent tonsillar herniation. The patient was in a poor medical condition, so could not decide on her treatment plan.

The patient immediately underwent sub-occipital craniactomy and excision of the well capsulated hemorrhagic lesion from the left cerebellar hemisphere (Figure 6). The patient made an uneventful recovery from the surgery and wound sutures were removed on the seventh day.

Histopathological study of the excised lesion showed diffuse cohesive sheets of trimorphic malignant trophoblasts, consisting of intermediate trophoblasts and cytotrophoblast, and rimmed with syncytiotrophoblast with the presence of a central hemorrhage and necrosis (Figure 7). The cells showed striking cytological atypia, high mitotic activity and absence of villi consistent to choriocarcinoma.

The CT chest of the patient following her surgery revealed a vascular right apical lesion (Figure 8).

A final diagnosis of multiple hemorrhagic lesions in the brain from primary lung choriocarcinoma was eventually made. The patient was referred to the National Cancer Centre for chemotherapy. The patient was started on the EMA-CO regime (Etoposide, Methotrexate and Actinomycin by drip over 2 days, followed by Cyclophosphamide and Oncovin the following week). The patient's B-HCG decreased sharply after the first session of chemotherapy (serum B-HCG dropped to $1,50,000 \mathrm{mIU} / \mathrm{ml}$ ). The patient was given three cycles of chemotherapy and has been on regular follow up at the cancer centre.

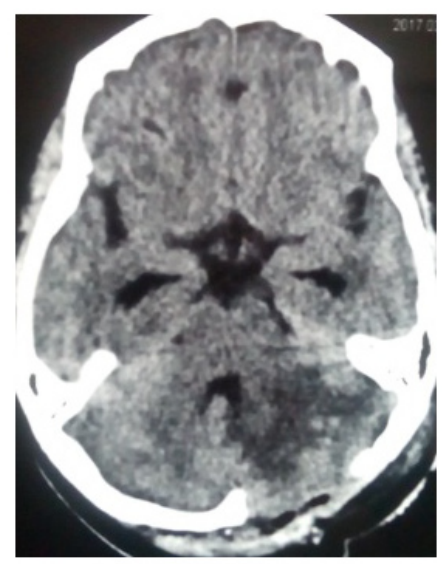

Figure 6. Post-operative CT image showing complete excision of the lesion in the posterior fossa.

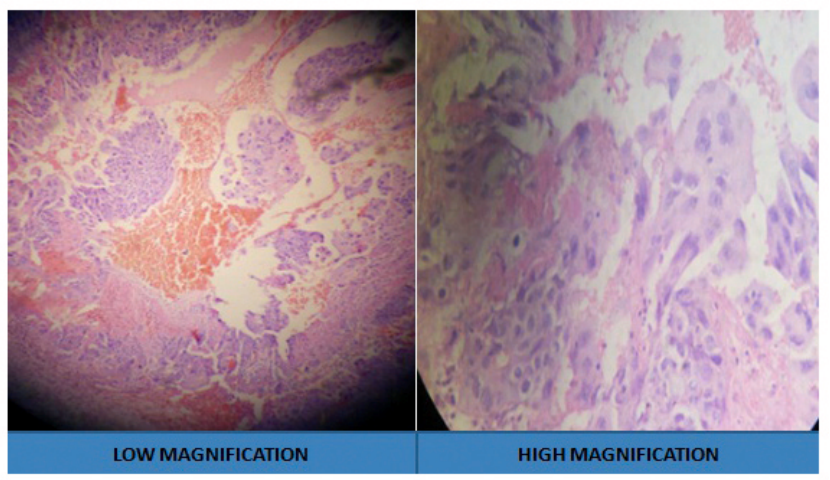

Figure 7. Histology image confirming the diagnosis of invasive choriocarcinoma.

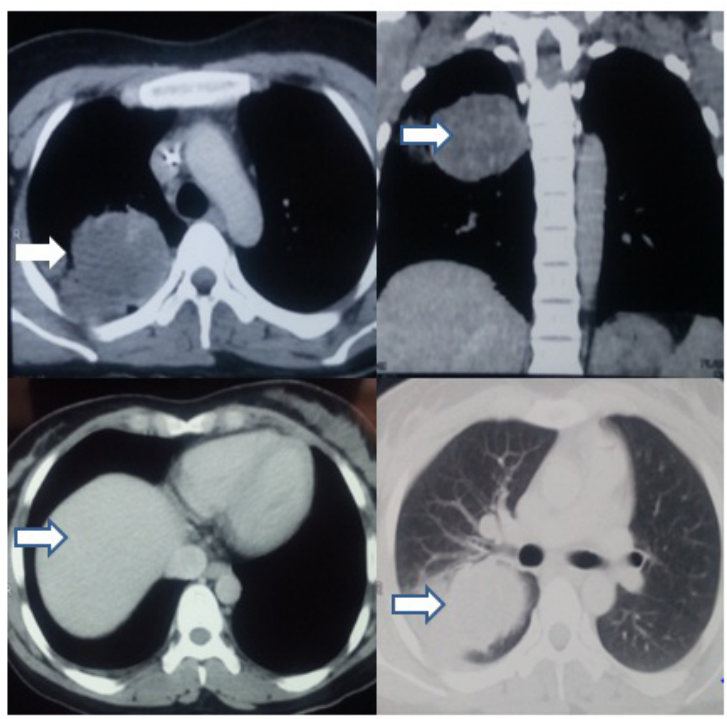

Figure 8. CT chest confirming presence of an enhanced and highly vascular lesion in the upper lobe of the right lung. 


\section{Discussion}

Primary lung choriocarcinoma is a very rare entity, with $<50$ cases reported currently ${ }^{2}$. This case report discusses an even rarer phenomenon of multiple hemorrhagic metastasis in the brain from primary lung choriocarcinoma.

There are various theories behind the etiology of primary lung choriocarcinoma. The foremost being embolism of trophoblastic cells during abortion, or even normal delivery, to the lung vasculature, thereby causing the cells to proliferate therein ${ }^{3}$. This may have occurred in the present case study. Other theories discuss the probable role of primordial germ cells and the genesis of metaplasia ${ }^{4}$. Choriocarcinoma can have either a gestational or non-gestational origin ${ }^{5,6}$.

Sometimes large cell anaplastic carcinoma, mediastinal germ cell tumor, bronchogenic carcinoma show ectopic HCG secretion, but this elevation is mild ${ }^{7,8}$. A high B-HCG level, as in our case, suggests a trophoblastic origin ${ }^{1}$.

The pathogenesis behind multiple hemorrhagic lesions in the brain is the tendency of such malignant trophoblastic cells to invade the vessels, and sometimes even leads to distal aneurysms ${ }^{9}$. Radiation has a poor response to such entity ${ }^{10}$. Therefore, the preferred therapy for gestational trophoblastic neoplasm is the EMA-CO regimen, similar to what was prescribed to our patient ${ }^{11}$.
The prognosis of the condition is poor, with previous reports of a 5 year survival of $<5 \%$. However, recent advancements in chemoradiation therapy has helped to increase the overall 5 year survival rate up to $50 \%{ }^{4,12}$. A multimodal approach is also required, constituting of neo-adjuvant chemotherapy followed by excision of the lung lesion?.

\section{Conclusions}

Primary lung choriocarcinoma metastasis should be recognized as a differential diagnosis in hemorrhagic lesions of the brain, especially in patients of a child bearing age. Early diagnosis and rapid initiation of therapy is the cornerstone for a better outcome in such patients.

\section{Consent}

Written informed consent for the publication of the clinical case study and accompanying images was taken from the patient.

\section{Competing interests}

No competing interests were disclosed.

\section{Grant information}

The author(s) declared that no grants were involved in supporting this work.
1. Rhee YK, Kim JH, Kim WH, et al:: Primary choriocarcinoma of the lung. Korean J Intern Med. 1987; 2(2): 269-272.

PubMed Abstract | Publisher Full Text | Free Full Text

2. Umemori $\mathrm{Y}$, Hiraki A, Aoe $\mathrm{K}$, et al:: Primary choriocarcinoma of the lung. Anticancer Res. 2004; 24(3b): 1905-1910. PubMed Abstract

3. Tanimura A, Natsuyama $\mathrm{H}$, Kawano $\mathrm{M}$, et al: Primary choriocarcinoma of the lung. Hum Pathol. 1985; 16(12): 1281-1284. PubMed Abstract | Publisher Full Text

4. Snoj Z, Kocijancic I, Skof E: Primary pulmonary choriocarcinoma. Radiol Oncol. 2017; 51(1): 1-7.

PubMed Abstract | Publisher Full Text | Free Full Text

5. Vegh GL, Szigetvári I, Soltesz I, et al:: Primary pulmonary choriocarcinoma: a case report. J Reprod Med. 2008; 53(5): 369-72. PubMed Abstract

6. Maestá I, Leite FV, Michelin OC, et al:: Primary pulmonary choriocarcinoma after human chorionic gonadotropin normalization following hydatidiform mole: a report of two cases. J Reprod Med. 2010; 55(7-8): 311-6. PubMed Abstract

7. Fusco FD, Rosen SW: Gonadotropin-producing anaplastic large-cell carcinomas of the lung. N Engl J Med. 1966; 275(10): 507-15 PubMed Abstract | Publisher Full Text

8. Hattori M, Imura $\mathrm{H}$, Matsukura $\mathrm{S}$, et al:: Multiple-hormone producing lung carcinoma. Cancer. 1979; 43(6): 2429-2437.

PubMed Abstract | Publisher Full Text

9. Sridhar KS, Saldana MJ, Thurer RJ, et al.: Primary choriocarcinoma of the lung: report of a case treated with intensive multimodality therapy and review of the literature. J Surg Oncol. 1989; 41(2): 93-7.

PubMed Abstract | Publisher Full Text

10. Pullar M, Blumbergs PC, Phillips GE, et al.: Neoplastic cerebral aneurysm from metastatic gestational choriocarcinoma. Case report. J Neurosurg. 1985; 63(4): 644-647.

PubMed Abstract | Publisher Full Text

11. Lurain JR, Singh DK, Schink JC: Primary treatment of metastatic high-risk gestational trophoblastic neoplasia with EMA-CO chemotherapy. J Reprod Med. 2006; 51(10): 767-72. PubMed Abstract

12. Berthod G, Bouzourene $\mathrm{H}$, Pachinger $\mathrm{C}$, et al:: Solitary choriocarcinoma in the lung. J Thorac Oncol. 2010; 5(4): 574-575.

PubMed Abstract | Publisher Full Text 


\section{Open Peer Review}

\section{Current Peer Review Status:}

\section{Version 1}

Reviewer Report 31 July 2017

https://doi.org/10.5256/f1000research.12619.r24086

(c) 2017 Thapa L. This is an open access peer review report distributed under the terms of the Creative Commons Attribution License, which permits unrestricted use, distribution, and reproduction in any medium, provided the original work is properly cited.

\section{Lekhjung Thapa}

Neuro and Allied Clinic, Bhairahawa, Nepal

I must congratulate the author for reporting such a rare medical entity. The case has been nicely described and I am sure that this is going to be useful for other practitioners. However, I feel, few points to be considered in this case report are:

1. Sixth CN palsies may be better demonstrated on all directions of gaze. In the given picture, it looks like the patient also has BL ptosis!

2. Histopathology of lung mass if included, would be better.

3. The patient has been on follow-up at cancer center. It would be interesting to know the neurological status at follow up.

4. I think the author should discuss more with data on brain metastasis of choriocarcinoma ${ }^{1}$.

\section{References}

1. Kobayashi T, Kida Y, Yoshida J, Shibuya N, et al.: Brain metastasis of choriocarcinoma.Surg Neurol . 1982; 17 (6): 395-403 PubMed Abstract

Is the background of the case's history and progression described in sufficient detail? Yes

Are enough details provided of any physical examination and diagnostic tests, treatment given and outcomes?

Partly

Is sufficient discussion included of the importance of the findings and their relevance to future understanding of disease processes, diagnosis or treatment? 
Partly

Is the case presented with sufficient detail to be useful for other practitioners?

Yes

Competing Interests: No competing interests were disclosed.

Reviewer Expertise: Neurology

I confirm that I have read this submission and believe that I have an appropriate level of expertise to confirm that it is of an acceptable scientific standard.

Reviewer Report 26 June 2017

https://doi.org/10.5256/f1000research.12619.r23780

(C) 2017 Wang P. This is an open access peer review report distributed under the terms of the Creative Commons Attribution License, which permits unrestricted use, distribution, and reproduction in any medium, provided the original work is properly cited.

\section{Ping Wang}

Department of Radiotherapy, Tianjin Medical University Cancer Institute and Hospital, Tianjin, China

The paper tells us "Her immune status was normal". I think the authors should show us the date of the immune test. Since the patient was found by multiple hemorrhagic metastases to the brain, and the primary lesion from lung, how about the tumor marker from lung? Has she had a gene test of EGFR, ROS1, ALK, T790M, which could be useful if she needed target therapy? Did she need radiation for the lung tumor and when? The author need to discuss these questions.

Is the background of the case's history and progression described in sufficient detail? Partly

Are enough details provided of any physical examination and diagnostic tests, treatment given and outcomes?

Yes

Is sufficient discussion included of the importance of the findings and their relevance to future understanding of disease processes, diagnosis or treatment? Partly

Is the case presented with sufficient detail to be useful for other practitioners? Yes

Competing Interests: No competing interests were disclosed. 
Reviewer Expertise: Radiation

I confirm that I have read this submission and believe that I have an appropriate level of expertise to confirm that it is of an acceptable scientific standard.

The benefits of publishing with F1000Research:

- Your article is published within days, with no editorial bias

- You can publish traditional articles, null/negative results, case reports, data notes and more

- The peer review process is transparent and collaborative

- Your article is indexed in PubMed after passing peer review

- Dedicated customer support at every stage

For pre-submission enquiries, contact research@f1000.com 